\title{
In Search of the Inverted Region: Chromophore-Based Driving Force Dependence of Interfacial Electron Transfer Reactivity at the Nanocrystalline Titanium Dioxide Semiconductor/Solution Interface ${ }^{\dagger}$
}

\author{
Susan G. Yan, Janice S. Prieskorn, Youngjin Kim, and Joseph T. Hupp* \\ Department of Chemistry and Materials Research Center, Northwestern University, Evanston, Illinois 60208
}

Received: April 27, 2000; In Final Form: June 20, 2000

\begin{abstract}
Intentional variations of the driving force for back electron transfer from titanium dioxide to a surface-bound redox couple, via synthetic alteration of the couple's formal potential, show that the reaction takes place in the Marcus normal region; i.e., rates become faster as the driving force increases. Variable-temperature rate measurements show that back ET is thermally activated, with the activation barrier decreasing with increasing driving force, as expected for a normal region process. The observation of normal region behavior, despite the existence of overall reaction driving forces that significantly exceed the likely reorganization energy, is attributed to the occurrence of a sequential electron- and proton-transfer process. The sequential process yields a driving force for the rate-determining electron-transfer step that is considerably smaller than the overall reaction driving force. The sequential electron- and proton-transfer mechanism also provides an explanation for the $\mathrm{pH}$ independence of the back-ET kinetics. Variable-temperature rate measurements additionally point toward a high degree of nonadiabaticity $-3-5$ orders of magnitude of rate attenuation due solely to inefficient electronic coupling. The physical basis for the effect presumably is in the need to traverse eight bonds, some of them saturated, in the back-ET process. Together with the barrier activation effects, the reaction nonadiabaticity accounts for the slow rates for back ET (ca. $10^{7} \mathrm{~s}^{-1}$ ) and, therefore, much of the ability of metal-to-ligand charge-transfer type chromophores to function effectively as sensitizers in $\mathrm{TiO}_{2}-$ based photoelectrochemical cells. The findings also suggest that more efficient cells could be constructed by extending the chemical linkage between the dye and semiconductor and by further decreasing the driving force for the back-ET process.
\end{abstract}

\section{Introduction}

Dye sensitization of wide band gap semiconductor electrodes in photoelectrochemical cells can lead to tremendous enhancements in efficiency in energy conversion applications by permitting such cells to respond to significant portions of the visible spectrum. ${ }^{1-3}$ Dye sensitization also provides a scheme for inititiating fast and ultrafast interfacial electron-transfer (ET) reactions, thereby permitting access to kinetic regimes that are interesting and important from a fundamental reactivity perspective, but are difficult or impossible to access via conventional electrochemical techniques. ${ }^{4-6} \mathrm{We}$ report here on the kinetics for back electron transfer for several variants of the classic tris polypyridyl ruthenium/nanocrystalline titanium dioxide system (eq 1). We note that this system has figured prominently in the development of several of the most promising current dye-based energy conversion systems ${ }^{7-14}$-in part because it was one of the first systems to exhibit both efficient forward electron transfer and comparatively slow back ET (but, nevertheless, fast by conventional electrochemical standards). Slow back reactivity is typically a criterion for achieving both a high degree of net charge separation and a high photovoltage. ${ }^{15}$ These characteristics, along with efficient photon collection, are essential for efficient overall device operation.

For dye/semiconductor combinations such as those in eq 1 , the induction of slow back-ET kinetics has typically been interpreted in terms of Marcus inverted region effects ${ }^{16-18}$ - where

† Part of the special issue "Thomas Spiro Festschrift".
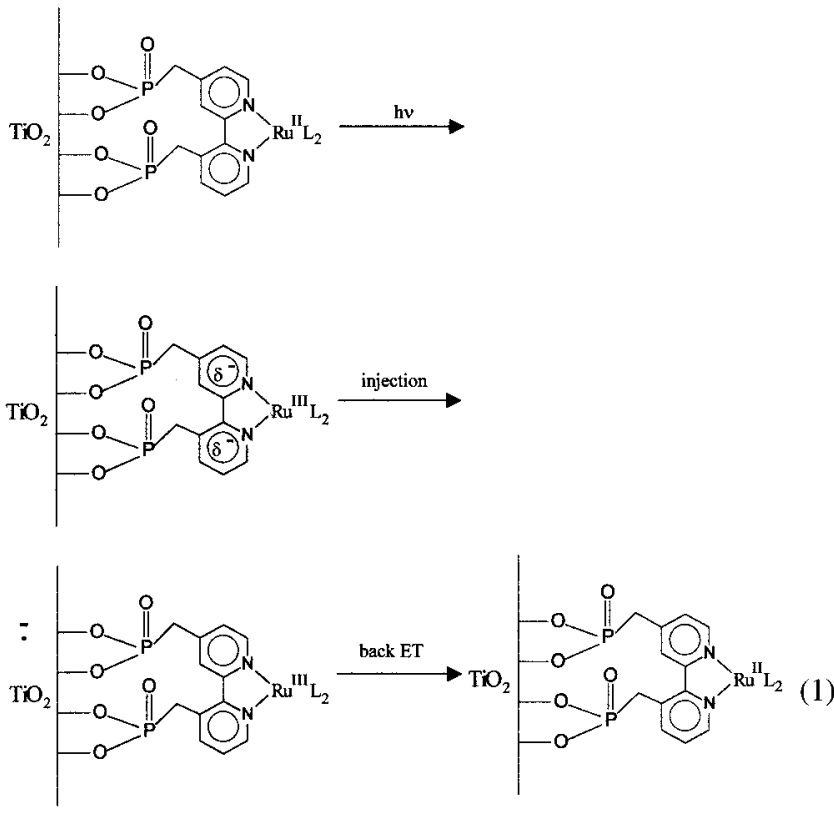

such effects indeed would be expected from the simplest reaction driving force $(\Delta G)$ and reorganization energy $(\lambda)$ considerations. ${ }^{19}$ We reasoned that the inverted region hypothesis could readily be verified by systematically altering $\Delta G$ and monitoring the effects upon the kinetics: Increases in driving force should yield exponential decreases in $k_{\text {bet }}$, the back electron-transfer 
rate constant. Surprisingly, we find that systematically increasing the reaction driving force instead significantly increases $k_{\text {bet }}$, implying that back electron transfer is occurring in the Marcus normal region. ${ }^{20,21}$ Variable-temperature kinetic studies, described below, provide further evidence for the unexpected normal region reactivity, while also pointing to the likely significance of nonadiabaticity in defining the kinetics. We find that a recently proposed alternative model for the energetics of selected reactions at metal oxide semiconductor/aqueous solution interfaces ${ }^{22-26}$ is capable of accommodating the otherwise incompatible observations of large overall interfacial reaction driving forces and well-defined Marcus normal region reactivity. Finally, we suggest that the findings have implications for electrochemical photovoltaic cell design and efficiency optimization.

\section{Experimental Section}

Materials. Colloidal $\mathrm{TiO}_{2}$ (ca. $8 \mathrm{~nm}$ diameter particles) and high surface area nanocrystalline films of $\mathrm{TiO}_{2}$ were prepared as described previously. ${ }^{14,27}$ Dyes were attached by immersing

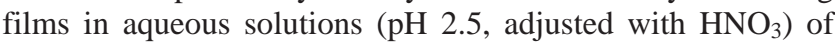
hydrolyzed dye for $24 \mathrm{~h}$, or by adding the hydrolyzed dye to a colloid sample and allowing it to stand for $24 \mathrm{~h}$.

Dye Syntheses. $\left[R u(d p b H)_{2} L\right]\left(P F_{6}\right)_{2}$ species $\left(\mathrm{dpbH}=4,4^{\prime}\right.$ $\left(\mathrm{CH}_{2} \mathrm{PO}(\mathrm{OH})_{2}\right)_{2}$-2,2'-bipyridine; $\mathrm{L}=1,10$-phenanthroline (phen), 5-nitro-1,10-phenanthroline ( $\mathrm{NO}_{2}$-phen), 5-methyl-1,10-phenanthroline $\left(\mathrm{CH}_{3}\right.$-phen), and 3,4,7,8-tetramethyl-1,10-phenanthroline $\left(\left(\mathrm{CH}_{3}\right)_{4}\right.$-phen) (GFS Chemicals); see the structures) were prepared from the corresponding phosphoester complexes by hydrolysis in $6 \mathrm{M} \mathrm{HCl}$. No attempt was made to isolate the resulting tetraphosphonic acid functionalized complexes as solids.

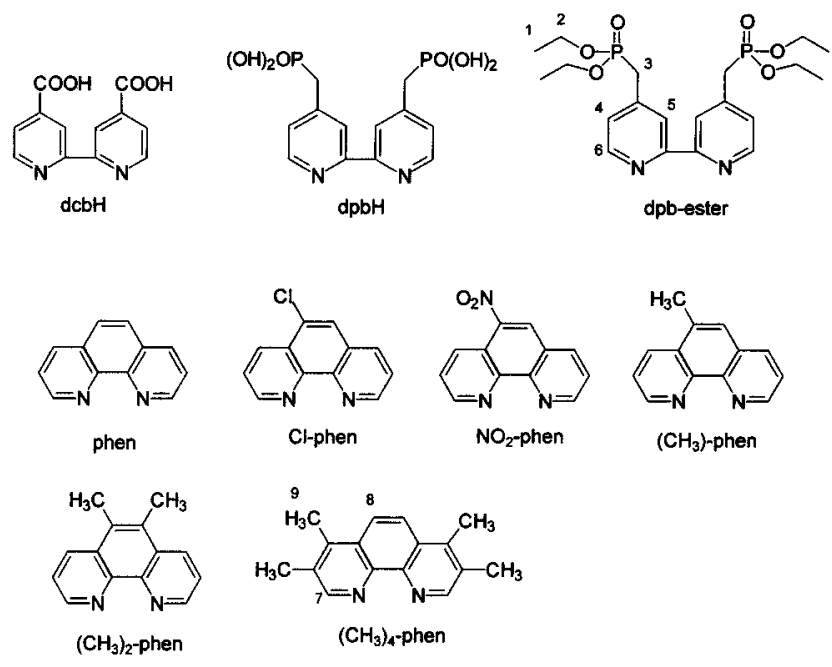

[Ru(dpb-ester $\left.)_{2} L\right]\left(\mathrm{PF}_{6}\right)_{2}$ species were prepared from $\mathrm{Ru}$ $(\mathrm{CO})_{2} \mathrm{LCl}_{2}$ and $4,4^{\prime}-\left(\mathrm{CH}_{2} \mathrm{PO}\left(\mathrm{OCH}_{2} \mathrm{CH}_{3}\right)_{2}\right)_{2}-2,2^{\prime}$-bipyridine (dpbester) by analogy to a literature method. ${ }^{28}$ Workup consisted of addition of aqueous $\mathrm{NH}_{4} \mathrm{PF}_{6}$, removal of solvent by rotary evaporation, dissolution of the residue in acetone followed by precipitation and filtration from stirring ether, redissolution in acetonitrile, passage through a short alumina column with 98:2 acetonitrile-methanol as eluent, partial removal of solvent, and isolation by filtration from stirring ether. Unfortunately, the compounds were contaminated with varying amounts of $\mathrm{NH}_{4}$ $\mathrm{PF}_{6}$, making characterization via elemental analysis uninformative. In contrast, FAB mass spectrometry did prove useful: $\left[\mathrm{Ru}(\mathrm{dpb} \text {-ester })_{2}(\mathrm{phen})\right]\left(\mathrm{PF}_{6}\right)_{2}$, m/e $1339\left(-\mathrm{PF}_{6}\right), 1195\left(-2\left(\mathrm{PF}_{6}\right)\right)$,
$1373\left(-4\left(\mathrm{C}_{2} \mathrm{H}_{4}\right)\right), 1138\left(-2\left(\mathrm{PF}_{6}\right),-2\left(\mathrm{C}_{2} \mathrm{H}_{4}\right)\right)$; $\left[\mathrm{Ru}(\mathrm{dpb}-\mathrm{ester})_{2}-\right.$ $\left(\mathrm{NO}_{2}\right.$-phen) $]\left(\mathrm{PF}_{6}\right)_{2}$, m/e 1529 (parent), $1384\left(-\mathrm{PF}_{6}\right), 1239$ $\left(-2\left(\mathrm{PF}_{6}\right)\right), 1339\left(-\mathrm{PF}_{6},-\mathrm{NO}_{2}\right), 1456\left(-\mathrm{C}_{2} \mathrm{H}_{4},-\mathrm{NO}_{2}\right), 1484$ $\left(-\mathrm{NO}_{2}\right), 1282\left(-\mathrm{PF}_{6},-2\left(\mathrm{C}_{2} \mathrm{H}_{4}\right),-\mathrm{NO}_{2}\right)$; $\left[\mathrm{Ru}(\mathrm{dpb} \text {-ester })_{2}\left(\mathrm{CH}_{3}-\right.\right.$ phen) $]\left(\mathrm{PF}_{6}\right)_{2}$, m/e 1499 (parent), $1353\left(-\mathrm{PF}_{6}\right), 1207\left(-2\left(\mathrm{PF}_{6}\right)\right)$, $1325\left(-\mathrm{C}_{2} \mathrm{H}_{4}\right), 1297\left(-2\left(\mathrm{C}_{2} \mathrm{H}_{4}\right)\right), 1179\left(-2\left(\mathrm{PF}_{6}\right),-\mathrm{C}_{2} \mathrm{H}_{4}\right), 1151$ $\left(-2\left(\mathrm{PF}_{6}\right)\right),-2\left(-\mathrm{C}_{2} \mathrm{H}_{4}\right) ;\left[\mathrm{Ru}(\text { dpb-ester })_{2}\left(\left(\mathrm{CH}_{3}\right)_{4}-\right.\right.$ phen $\left.)\right]\left(\mathrm{PF}_{6}\right)_{2}$, m/e $1398\left(-\mathrm{PF}_{6}\right), 1253\left(-2\left(\mathrm{PF}_{6}\right)\right), 1225\left(-2\left(\mathrm{PF}_{6}\right),-\mathrm{C}_{2} \mathrm{H}_{4}\right)$, 1384 (-PF6, $\left.-\mathrm{CH}_{2}\right), 1169\left(-2\left(\mathrm{PF}_{6}\right),-3\left(\mathrm{C}_{2} \mathrm{H}_{4}\right)\right)$.

In addition, the precursor compound $\left[\mathrm{Ru}(\mathrm{dpb} \text {-ester })_{2}\left(\left(\mathrm{CH}_{3}\right)_{4}\right.\right.$ phen $)]\left(\mathrm{PF}_{6}\right)_{2}$ gave the following ${ }^{1} \mathrm{H}$ NMR $\left(\mathrm{D}_{2} \mathrm{O}\right)$ spectrum: $\delta$ $1.3\left(\mathrm{H}_{1}, \mathrm{t}, J=10.6 \mathrm{~Hz}, 12 \mathrm{H}\right), 4.1\left(\mathrm{H}_{2}, \mathrm{q}, J=8.8 \mathrm{~Hz}, 8 \mathrm{H}\right), 3.5$ $\left(\mathrm{H}_{3}, 2 \mathrm{~s}, 4 \mathrm{H}\right), 8.2\left(\mathrm{H}_{5}, \mathrm{~s}, 2 \mathrm{H}\right), 8.7\left(\mathrm{H}_{6}, \mathrm{~d}, 2 \mathrm{H}\right), 7.9,9.2\left(\mathrm{H}_{7}, \mathrm{H}_{8}\right.$, $\mathrm{m}, 4 \mathrm{H}), 2.9,3.0\left(\mathrm{H}_{9}, 2,12 \mathrm{H}\right)$. Following treatment with $6 \mathrm{M}$ $\mathrm{HCl}$, the peaks at $\delta 1.3$ and 4.1 were lost, confirming loss of the ester groups.

$\mathrm{Ru}(\mathrm{CO})_{2} \mathrm{LCl}_{2}$ species were prepared from $\left[\mathrm{Ru}(\mathrm{CO})_{2} \mathrm{Cl}_{2}\right]_{n}{ }^{29}$ and $\mathrm{L}$ via published procedures. ${ }^{30}$

$\left[\mathrm{Ru}(\mathrm{dcbH})_{2} \mathrm{~L}\right] \mathrm{Na}_{2}$ species (dcbH $=2,2^{\prime}$-bipyridine-4,4'-dicarboxylic acid; $\mathrm{L}=5$,6-dimethyl-1,10-phenanthroline $\left(\left(\mathrm{CH}_{3}\right)_{2^{-}}\right.$ phen), 5-chloro-1,10-phenanthroline (Cl-phen), and $\mathrm{NO}_{2}$-phen) were synthesized according to the method of Crutchley and coworkers. ${ }^{31}$ In some cases the desired compound could be isolated only as a powder contaminated with $\mathrm{NaCl}$ (used for precipitation of the highly water soluble complexes). Elem anal. for [Ru$(\mathrm{dcbH})_{2}\left(\left(\mathrm{CH}_{3}\right)_{2}\right.$-phen $\left.)\right] \mathrm{Na}_{2} \cdot 8 \mathrm{H}_{2} \mathrm{O} \cdot \mathrm{NaCl}\left(=\mathrm{RuC}_{38} \mathrm{H}_{40} \mathrm{~N}_{6} \mathrm{O}_{16} \mathrm{Na}_{3}-\right.$ $\mathrm{Cl}$ ) calcd (found): C, 43.53 (43.79); H, 3.64 (3.87); N, 8.44 (8.06). Elem anal. for $\left[\mathrm{Ru}(\mathrm{dcbH})_{2}(\mathrm{Cl}\right.$-phen $\left.)\right] \mathrm{Na}_{2} \cdot 8 \mathrm{H}_{2} \mathrm{O}$ (= $\mathrm{RuC}_{36} \mathrm{H}_{36} \mathrm{~N}_{6} \mathrm{O}_{16} \mathrm{ClNa}_{2}$ ) calcd (found): C, 43.02 (43.67); $\mathrm{H}$, 3.5 (3.56); N, 9.18 (8.49). Elem anal. for $\left[\mathrm{Ru}(\mathrm{dcbH})_{2}\left(\mathrm{NO}_{2-}\right.\right.$ phen) $] \mathrm{Na}_{2} \cdot 5 \mathrm{H}_{2} \mathrm{O} \cdot 4 \mathrm{NaCl}\left(=\mathrm{RuC}_{36} \mathrm{H}_{30} \mathrm{~N}_{7} \mathrm{O}_{15} \mathrm{Na}_{2} \cdot 5 \mathrm{H}_{2} \mathrm{O} \cdot 4 \mathrm{NaCl}\right)$ calcd (found): C, 36.89 (36.63); H, 2.81 (2.48); N, 8.25 (8.31).

Measurements. Transient absorbance measurements were performed with colloidal samples by using the frequencydoubled output of a short-cavity, short-pulse, Q-switched Nd: YAG laser for sample excitation and a pulsed xenon lamp as a probe, as previously described. ${ }^{14}$ The minimal response time of the instrument is ca. $5 \mathrm{~ns}$. Rate data typically were collected at $\sim 460 \mathrm{~nm}$. Temperature variations between ca. $23^{\circ}$ (ambient temperature) and $10{ }^{\circ} \mathrm{C}$ were achieved by immersing the sample cuvette in a stirring water bath. Systematic variations between ca. $23^{\circ}$ and $60{ }^{\circ} \mathrm{C}$ were achieved by wrapping the sample cuvette with a heating tape connected to a Variac controller.

Formal potentials, $E_{\mathrm{f}}$, for titanium dioxide bound phosphonate dyes were determined by recording voltammograms directly using relatively thin and comparatively highly loaded films of $\mathrm{TiO}_{2}{ }^{32}$ The estimated uncertainty was $\pm 0.01 \mathrm{~V}$. Potentials obtained in this way agree with those obtained spectroelectrochemically by loading dyes onto high-area $\mathrm{TiO}_{2}$ films and utilizing redox mediators as described previously. ${ }^{33}$ The direct voltammetry method, however, yielded lower uncertainties, making it the preferred approach. Formal potentials for mixedligand carboxylate dyes were estimated from literature values for $\mathrm{Ru}\left(4,4^{\prime}-\mathrm{COO}^{-}-2,2^{\prime}-\text { bpy }\right)_{3}{ }^{3-/ 4-}$ and $\mathrm{RuL}_{3}{ }^{3+/ 2+}$ species. ${ }^{34}$ The potential for the hexacarboxylated complex is reportedly unchanged by attachment to $\mathrm{TiO}_{2}$; we assumed that the potentials for mixed-ligand complexes also would be unaffected. (In contrast, the potentials of the phosphonate dyes are known to shift to less positive values upon surface attachement.) Unfortunately, the carboxylate dyes were consumed some time before the surface spectroelectrochemical methodology was developed. It is conceivable, therefore, that the true $E_{\mathrm{f}}$ values differ slightly from the estimates. Relative values within the carboxylate series, however, should be accurate. 
TABLE 1: Reactants and Driving Forces

\begin{tabular}{llcc}
\hline \multicolumn{1}{c}{ complex } & $E_{\mathrm{f}}, \mathrm{V}$ vs SSCE & $\Delta G^{\circ}$ (overall rxn), ${ }^{a} \mathrm{eV}$ \\
\hline $\mathbf{1}$ & $\mathrm{Ru}(\mathrm{dpb})_{2}\left(\mathrm{NO}_{2} \text {-phen }\right)^{6-}$ & 0.93 & -1.45 \\
$\mathbf{2}$ & $\mathrm{Ru}(\mathrm{dpb})_{2}(\text { phen })^{6-}$ & 0.89 & -1.41 \\
$\mathbf{3}$ & $\mathrm{Ru}(\mathrm{dpb})_{2}\left(\mathrm{CH}_{3} \text {-phen }\right)^{6-}$ & 0.86 & -1.38 \\
$\mathbf{4}$ & $\mathrm{Ru}(\mathrm{dpb})_{2}\left(\left(\mathrm{CH}_{3}\right)_{4} \text {-phen }\right)^{6-}$ & 0.68 & -1.13 \\
$\mathbf{5}$ & $\mathrm{Ru}(\mathrm{dcb})_{2}\left(\mathrm{NO}_{2} \text {-phen }\right)^{2-}$ & 1.08 & -1.60 \\
$\mathbf{6}$ & $\mathrm{Ru}(\mathrm{dcb})_{2}\left(\mathrm{Cl}_{\text {-phen }}\right)^{2-}$ & 0.98 & -1.50 \\
$\mathbf{7}$ & $\mathrm{Ru}(\mathrm{dcb})_{2}\left(\mathrm{CH}_{3}\right)_{2}$-phen $)^{2-}$ & 0.82 & -1.34
\end{tabular}

${ }^{a}$ Calculated at $\mathrm{pH} 3$ by assuming a conduction band edge energy of $-0.52 \mathrm{~V}$.

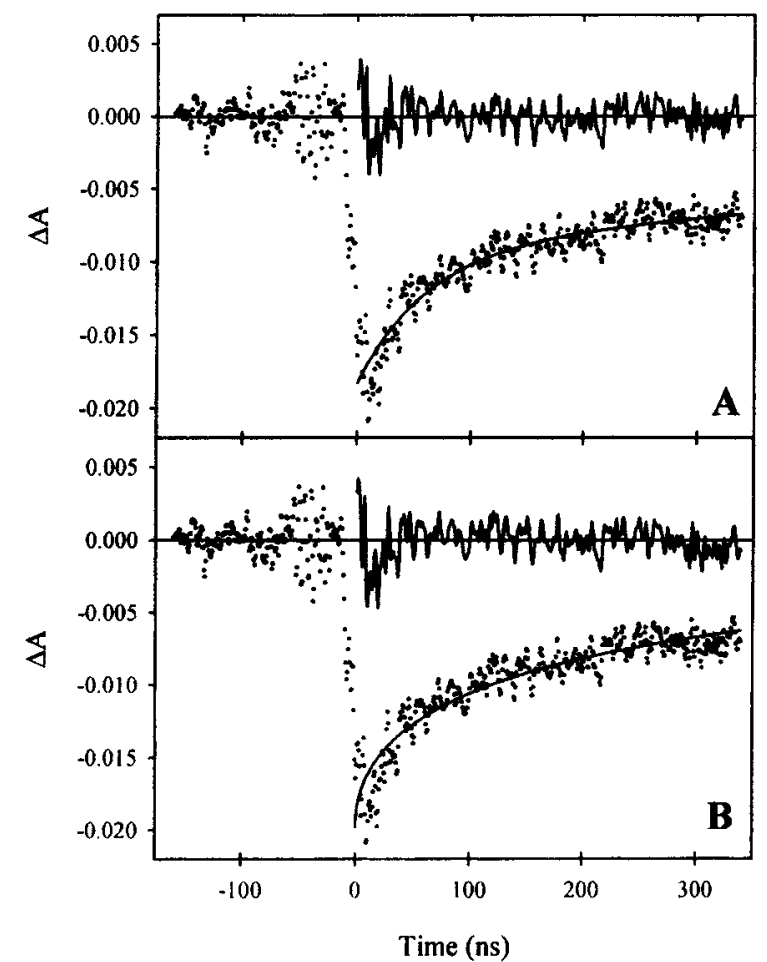

Figure 1. Absorbance transient for $\mathrm{Ru}(\mathrm{dpb})_{2}\left(\mathrm{CH}_{3}-\mathrm{phen}\right)^{6-15-}$ on collodidal $\mathrm{TiO}_{2}$. The initial bleach is assigned to electron injection; the slower recovery is assigned to back electron transfer. Panel A: a fit to a biexponential function (eq 2); residuals also shown. Panel B: a fit to the KWW function (eq 3); residuals also shown.

\section{Results}

Table 1 lists measured and estimated metal-centered formal potentials, respectively, for phosphonate- and carboxylatefunctionalized dye complexes. Also listed are apparent back reaction driving forces (semiconductor to $\mathrm{Ru}(\mathrm{III})$ ) at $\mathrm{pH} 3$. Note that the apparent driving forces will change by approximately $-60 \mathrm{mV}$ per unit increase in solution $\mathrm{pH}$.

Figure 1 shows a representative transient absorbance signal for complex 3 on $\mathrm{TiO}_{2}$. Consistent with previous reports, the initial bleach is assigned to metal-to-ligand charge-transfer (MLCT) excitation and rapid forward electron transfer (electron injection; eq 1). The slower recovery is assigned to back ET, eq 1. Again in agreement with prior reports for related systems, the recovery clearly is nonexponential. Furthermore, its shape, at least over the time regime sampled, is essentially independent of the pump laser intensity. As indicated in Figure 1a, the absorbance transient was initially fit to a biexponential recovery expression, eq 2. Justification for the biexponential fit comes

$$
\Delta A / \Delta A_{0}=a\left[1-\exp \left(-k_{1} t\right)\right]+b\left[1-\exp \left(-k_{2} t\right)\right]+
$$

TABLE 2: Ambient Temperature Rate Parameters for Back Electron Transfer

\begin{tabular}{cccc}
\hline complex & $k_{1} \times 10^{-6}, \mathrm{~s}^{-1}$ & $k_{\mathrm{c}} \times 10^{-6}, \mathrm{~s}^{-1}$ & $\beta$ \\
\hline $\mathbf{1}$ & 13 & 8 & 0.43 \\
$\mathbf{2}$ & 8 & 5.5 & 0.48 \\
$\mathbf{3}$ & 7 & 4 & 0.51 \\
$\mathbf{4}$ & 7 & 4 & 0.45 \\
$\mathbf{5}$ & 25 & & \\
$\mathbf{6}$ & 17 & & \\
$\mathbf{7}$ & 10 & &
\end{tabular}

from earlier observations for the parent complex $\mathrm{Ru}^{\mathrm{III}}(\mathrm{dpbH})_{3}{ }^{9-}$ on thin-film titanium dioxide electrodes. ${ }^{14}$ In those studies, we found that, by poising the electrode potential at a value just positive of the apparent conduction band edge, the initially complicated recovery kinetics could be reduced to approximately single-exponential kinetics. The behavioral simplification was attributed to filling of surface states located positive of the apparent conduction band edge, where the filling process prevents the states from participating in either the electron injection or the back electron-transfer process. The filling process also presumably precludes their participation as secondary traps.

For the data in Figure 1, the kinetic parameters obtained were $k_{1}=1.7 \times 10^{7} \mathrm{~s}^{-1}, a=0.49, k_{2}=1.5 \times 10^{6} \mathrm{~s}^{-1}$, and $b=$ $0.37 .{ }^{35}$ We previously showed for the parent complex $\mathrm{Ru}(\mathrm{dpbH}) 3^{9-/ 10-}$ that $k_{1}$ is insensitive to solution $\mathrm{pH}(19 \mathrm{pH}$ unit range), despite the dependence of the apparent back reaction driving force on $\mathrm{pH} .{ }^{14}$ The data in Figure 1 were also fit to the following version of the Kohlrausch-Williams-Watts (KWW) expression: ${ }^{36,37}$

$$
\Delta A / \Delta A_{0}=\exp \left[-\left(t / \tau_{\mathrm{c}}\right)^{\beta}\right]
$$

In eq $3, \Delta A$ is the time-dependent change in absorbance and $t$ is time. If $\mathrm{KWW}$ behavior is attributed exclusively to the phenomenon of distributed kinetics, then the fitting parameter, $\tau_{\mathrm{c}}$, can be regarded as the most probable electron-transfer reaction lifetime and $k_{\mathrm{c}}$ can be regarded as the most probable rate constant. The parameter $\beta$, which can assume values between 0 and 1 , is inversely proportional to the width of the rate distribution. From Figure $1 \mathrm{~b}, k_{\mathrm{c}}=4 \times 10^{6} \mathrm{~s}^{-1}$ and $\beta=$ 0.50 . From the residuals in Figure 1, the KWW fit is somewhat less satisfactory than the biexponentional fit, at least over the time interval examined. It is conceivable, however, that the KWW approach would prove superior if fits to transients of several microseconds duration were attempted. Unfortunately, probe lamp instabilities prevented us from obtaining accurate transient absorbance data beyond about $1 \mu \mathrm{s}$.

Back electron-transfer rate constants for the seven functionalized dyes are summarized in Table 2. It should be noted that, for a given metal complex, measured rate constants varied by as much as a factor of 2, depending on the identity and/or age of the $\mathrm{TiO}_{2}$ colloid sample used. Consequently, rate comparisons among complexes in a given family are made only with data sets collected with a common colloid preparation. In Figure 2 the available $k_{1}$ values are plotted versus the apparent back reaction driving force, given by the difference between the estimated conduction band edge energy $\left(E_{\mathrm{cb}}\right)$ at $\mathrm{pH} 3$ and the pertinent $\mathrm{Ru}^{\mathrm{II} / \mathrm{II}}$ formal potential. Note that for both the carboxylate dye series and the phosphonate dye series, $k_{1}$ increases as the driving force increases; i.e., Marcus normal region behavior is evidently encountered. ${ }^{38}$ Note further that the alternative KWW analysis (Table 2) also yields-perhaps more persuasively-apparent normal region behavior.

Because significant thermal activation is a distinctive normal region behavior as opposed to inverted region behavior, we also 


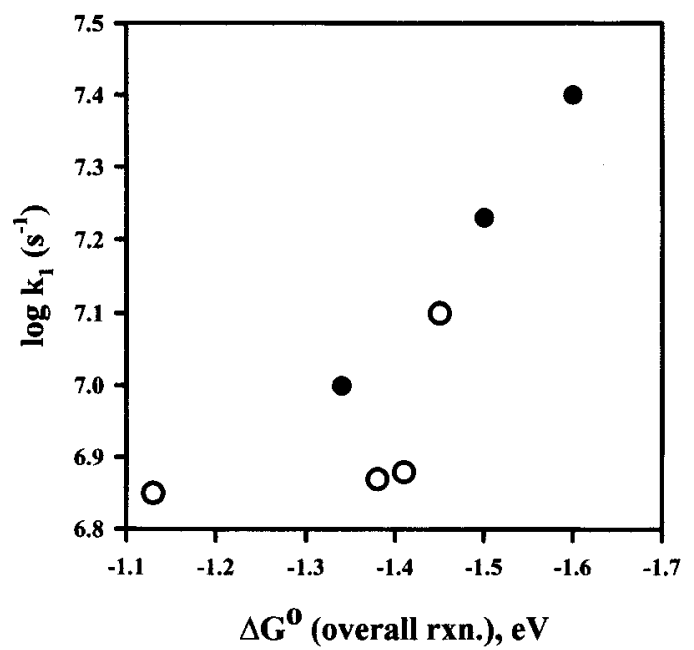

Figure 2. The log of the back electron-transfer rate constant $\left(k_{1}\right.$; eq $3)$ versus the overall reaction driving force. Open circles: $\mathrm{Ru}(\mathrm{dpb})_{2} \mathrm{~L}^{6-15-}$ couples. Filled circles: $\mathrm{Ru}(\mathrm{dcb})_{2} \mathrm{~L}^{2-11-}$ couples.

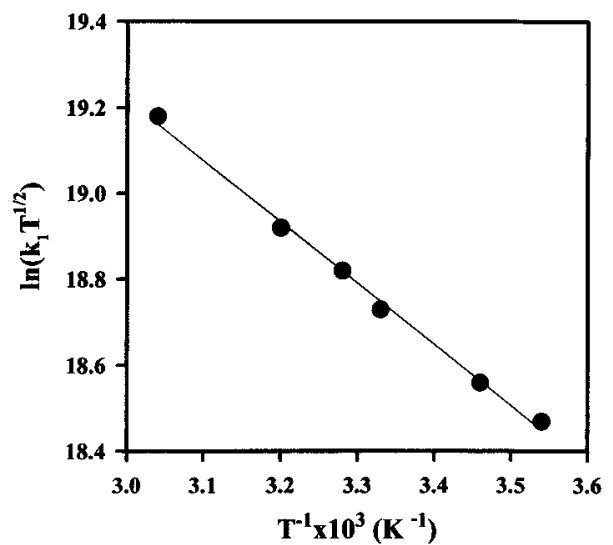

Figure 3. Modified "Arrhenius" plot for back electron transfer from colloidal $\mathrm{TiO}_{2}$ to $\mathrm{Ru}(\mathrm{dpb})_{2}(\text { phen })^{5-}$.

examined the effect of temperature upon back electron-transfer reactivity. ${ }^{39}$ Unfortunately, because of carboxylate dye desorption problems at elevated temperatures, data could be obtained only for the phosphonated complexes. Figure 3 shows representative temperature dependence data for back ET to complexes 1-4. If a classical Marcus-type rate formulation is assumed, but with a nonadiabatic, quantum mechanical prefactor (see below), then the slopes of the plots in Figure 3 will yield activation enthalpies, $\Delta H^{*}$. Figure 4 shows that the activation enthalpies are finite and positive and that they systematically decrease with increasing apparent back reaction driving force. Listed in Table 3 are apparent back-ET frequency factors (derived from Figure 3 intercepts and eq 4). Notably, these are

$$
\begin{aligned}
& k(\text { back ET })=k_{1}= \mathrm{A} \exp \left(-\Delta H^{*} / R T\right)= \\
&\left(\pi H_{\mathrm{ab}}{ }^{2} / \hbar\right)\left(\pi \lambda_{\mathrm{s}} / R T\right)^{-1 / 2} \exp \left(-\Delta H^{*} / R T\right)
\end{aligned}
$$

3-5 orders of magnitude smaller than would be expected if solvent or vibrational motion controlled the back reaction dynamics. In eq $4, \hbar$ is Planck's constant divided by $2 \pi, H_{\mathrm{ab}}$ is the initial-state/final-state electronic coupling matrix element, $\lambda_{\mathrm{s}}$ is the sum of solvent and low-frequency vibrational reorganizational energy contributions, $R$ is the gas law constant, and $T$ is temperature. Furthermore, for simplicity, $\Delta H^{*}$ has been equated with $\Delta G^{*}$; clearly, however, if a finite activation entropy exists, $H_{\mathrm{ab}}$ will differ from the value obtained via eq 4 .

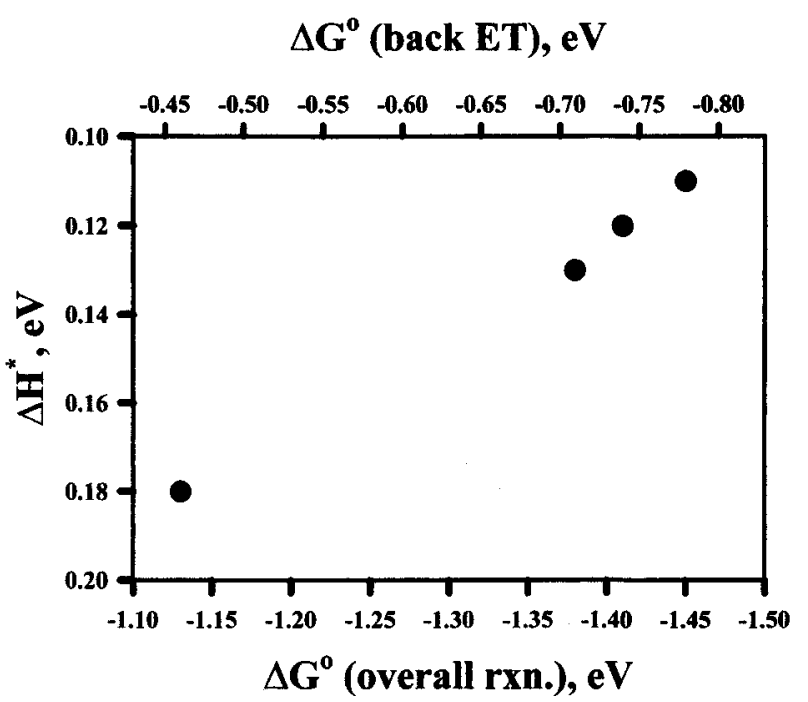

Figure 4. $\Delta H^{*}$ for back electron transfer versus the overall reaction driving force (bottom axis label) and versus the estimated driving force for the electron-transfer step in isolation (top axis label).

TABLE 3: Apparent Activation Parameters and Electronic Coupling Parameters for Back Electron Transfer

\begin{tabular}{cccccc}
\hline complex & $\begin{array}{c}\Delta G^{\circ}(\text { back ET) } \\
\mathrm{eV}\end{array}$ & $\begin{array}{c}\Delta H^{*}, \\
\mathrm{eV}\end{array}$ & \multicolumn{1}{c}{$A, \mathrm{~s}^{-1}$} & $\begin{array}{c}H_{\mathrm{ab}}, \\
\mathrm{cm}^{-1}\end{array}$ & $\begin{array}{c}\text { temp } \\
\text { range, }{ }^{\circ} \mathrm{C}\end{array}$ \\
\hline $\mathbf{1}$ & -0.78 & 0.11 & $8 \times 10^{9}$ & 1.7 & $12-37$ \\
$\mathbf{2}$ & -0.74 & 0.12 & $1.3 \times 10^{9}$ & 1.8 & $10-60$ \\
$\mathbf{3}$ & -0.71 & 0.13 & $9 \times 10^{8}$ & 2.3 & $28-60$ \\
$\mathbf{4}$ & -0.53 & 0.18 & $8 \times 10^{8}$ & 5 & $27-52$
\end{tabular}

\section{Discussion}

Barriers. Any mechanistic interpretation of the comparatively slow electron-transfer process associated with the rutheniumbased sensitizing dyes must account for the following, somewhat contradictory, observations: (a) reactions are thermally activated, (b) the driving force dependence is normal, rather than inverted, (c) overall driving forces are large, apparently exceeding the total reorganization energy, ${ }^{40,41}$ (d) preexponentional factors are relatively small, and (e) rates are $\mathrm{pH}$ independent. The combination of finding $\mathrm{c}$ and observations $\mathrm{a}, \mathrm{b}$, and $\mathrm{e}$ appears to rule out a conventional mechanism involving electron transfer from the bottom of the titanium dioxide conduction band. Indeed, such a mechanism should yield inverted, temperature-independent kinetic behavior, with rate constants that exponentially decrease as the $\mathrm{pH}$ is elevated. ${ }^{18,42}$

Scheme 1 and Figure 5 illustrate an alternative, trap-state mechanism that does accommodate the available observations. The scheme is based, in part, on the recent discovery that electron addition to metal oxide semiconductor electrodes is accompanied by charge-compensating cation uptake-protons in the case of water, supporting electrolyte cations in the case of acetonitrile or propylene carbonate..$^{22-26,43-45}$ The essence of the scheme is that charge localization in trap states permits electrons and protons to be transferred sequentially.

Figure 5 illustrates the corresponding energetic consequences. The combination (eqs 9 and 10) of electron transfer and proton transfer from localized titanium surface states to $\mathrm{Ru}^{\mathrm{III}}$ and the solvent, respectively, yields an overall reaction driving force that is $\mathrm{pH}$ dependent. (Compelling evidence for redox-induced proton transfer involving near-band-edge surface states has been obtained previously via quartz crystal microbalance experiments. $)^{22-26}$ In the figure, the overall driving force is given by the difference in potential between the $\mathrm{Ti}^{\mathrm{IV}}(\mathrm{O})_{2} / \mathrm{Ti}^{\mathrm{III}}(\mathrm{O})(\mathrm{OH})$ couple (diagonal solid line) and the pertinent $\mathrm{Ru}$ III/II couple. On 


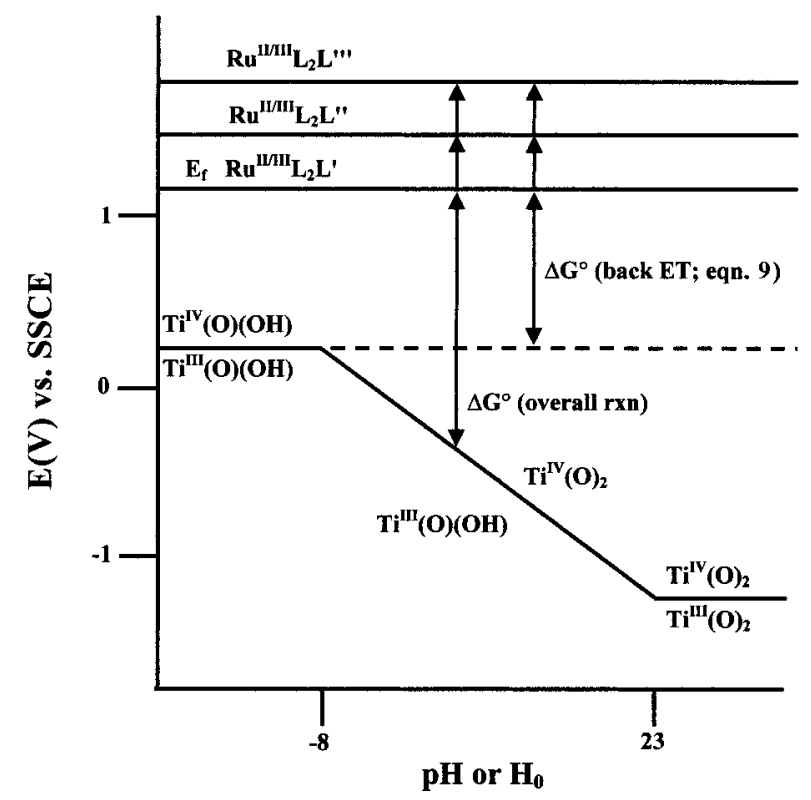

Figure 5. Modified Pourbaix diagram illustrating pH-dependent and $\mathrm{pH}$-independent back reaction energetics.

\section{Scheme 1}

$$
\begin{aligned}
& \mathrm{Ru}^{\mathrm{II}} \mathrm{L}_{3}{ }^{6-}+\mathrm{TiO}_{2} \stackrel{h v}{\longrightarrow} \mathrm{Ru}^{\mathrm{III}} \dot{L}^{\circ} \mathrm{L}_{2}{ }^{6-}+\mathrm{TiO}_{2} \quad \text { excitation } \\
& \mathrm{Ru}^{\mathrm{III}} \dot{\mathrm{L}}_{2}{ }^{* 6-}+\mathrm{TiO}_{2} \rightarrow \mathrm{Ru}{ }^{\mathrm{III}} \mathrm{L}_{3}{ }^{5-}+\mathrm{TiO}_{2}\left(\mathrm{e}_{\mathrm{cb}}{ }^{-}\right) \\
& \text {injection (6) } \\
& \mathrm{Ru}^{\mathrm{III}} \mathrm{L}_{3}{ }^{5-}+\mathrm{TiO}_{2}\left(\mathrm{e}_{\mathrm{cb}}{ }^{-}\right) \rightarrow \mathrm{Ru}^{\mathrm{III}} \mathrm{L}_{3}{ }^{5-}+\mathrm{Ti}^{\mathrm{iII}} \mathrm{O}_{2} \text { trapping } \\
& \mathrm{Ru}^{\mathrm{III}} \mathrm{L}_{3}{ }^{5-}+\mathrm{Ti}^{\mathrm{III}} \mathrm{O}_{2}+\mathrm{H}^{+} \rightarrow \\
& \mathrm{Ru}^{\mathrm{III}} \mathrm{L}_{3}{ }^{5-}+\mathrm{Ti}^{\mathrm{III}}(\mathrm{O})(\mathrm{OH}) \\
& \text { uptake (8) } \\
& \mathrm{Ru}^{\mathrm{III}} \mathrm{L}_{3}{ }^{5-}+\mathrm{Ti}^{\mathrm{iII}}(\mathrm{O})(\mathrm{OH}) \rightarrow \\
& \mathrm{Ru}^{\mathrm{II}} \mathrm{L}_{3}{ }^{6-}+\mathrm{Ti}^{\mathrm{IV}}(\mathrm{O})(\mathrm{OH}) \\
& \text { back ET (9) } \\
& \mathrm{Ru}^{\mathrm{II}} \mathrm{L}_{3}{ }^{6-}+\mathrm{Ti}^{\mathrm{IV}}(\mathrm{O})(\mathrm{OH}) \rightarrow \\
& \mathrm{Ru}^{\mathrm{II}} \mathrm{L}_{3}{ }^{6-}+\mathrm{TiO}_{2}+\mathrm{H}^{+} \quad \text { expulsion }
\end{aligned}
$$

the other hand, if electron transfer and proton transfer occur sequentially, then the thermodynamic driving force for the ET step in isolation (eq 9) clearly will be $\mathrm{pH}$ independent; in Figure 5 , this driving force is given by the difference in potential for the $\mathrm{Ti}^{\mathrm{IV} / \mathrm{III}}(\mathrm{O})(\mathrm{OH})$ couple (dashed line in Figure 5) and the pertinent $\mathrm{Ru}^{\mathrm{III} / \mathrm{II}}$ couple.

If eq 9 is the rate-determining step in the overall back reaction sequence, then only its driving force $\left(\Delta G^{\circ}\right.$ (back ET); Table 3$)$, not the overall driving force, will appear in the conventional Marcus-type rate constant expression:

$$
k(\text { back ET })=k_{1}=\mathrm{A} \exp \left\{-\left(\lambda+\Delta G^{\circ}\right)^{2} / 4 \lambda R T\right\}
$$

Given the $\mathrm{pH}$ independence of the isolated ET driving force, eq 11 necessarily yields (according to this scheme) a pHindependent rate constant. Additionally, it is important to note that except at the very lowest $\mathrm{pH}$ or $H_{0}$ values, the driving force for the kinetically relevant isolated ET step (eq 9, only) is less than the driving force for the overall reaction (eqs $9+10$ ). Given the smaller driving force, less reorganization energy would be needed to obtain Marcus normal region behavior and thermally activated electron transfer. Indeed, a reorganization energy as small as $1 \mathrm{eV}$ would be sufficient, in this scheme, to yield normal Marcus behavior and meaurable activation enthalpies.

Dynamics. The preexponential factors in Table 3 indicate that back ET likely occurs in the nonadiabatic regime: The values are 3-5 orders of magnitude smaller than expected on the basis of solvational or metal-ligand vibrational dynamical control. If activation entropy contributions can be neglected, ${ }^{46}$ the preexponential factors can be used to estimate, via eq 4 , the electronic coupling matrix element. The values obtained (Table 3) range from 1.7 to $5 \mathrm{~cm}^{-1}$.

As suggested by the linkage structure in eq 1, the small $H_{\mathrm{ab}}$ values are an expected consequence of the need to traverse eight bonds in the back-electron-transfer reaction (eq 9). Forward ET (injection; eq 6), on the other hand, involves only four intervening bonds since it originates from a delocalized ligand $\pi^{*}$ orbital. Presumably, $H_{\mathrm{ab}}$ is correspondingly larger, with the larger value accounting, in part, for the faster rate for this process.

Energy Conversion Implications. The mechanistic findings illustrated in Figure 2, Scheme 1, and eq 1 might have significant implications in the context of dye-sensitized solar cell design and optimization. For MLCT-type chromophores, an interesting trade-off is implied if back electron transfer occurs in the Marcus inverted region: Lowering the metal redox potential by changing the identity of nonchromophoric ligands should extend a given chromophore's red absorption edge (lower the metal/chromophoric ligand energy gap) and thereby permit the chromophore to absorb a larger fraction of the solar spectrum. (For simplicity, we assume that higher lying excited states are available to maintain blue absorption.) A lower metal-based redox potential, on the other hand, implies a smaller semiconductor-to-molecule driving force for the back-electron-transfer process. If back ET is inverted, then $k_{\text {bet }}$ will increase and the device efficiency will likely suffer. On the other hand, if back ET occurs in the normal region, then $k_{\text {bet }}$ should decrease and the device efficiency will not be damaged. We suggest that the already demonstrated success of the red-absorbing complex $\mathrm{Ru}(\mathrm{dcb})_{2}(\mathrm{SCN})_{2}{ }^{4-}$ as semiconductor sensitizer might be duein part, and at the shortest time scales-to normal region behavior: The $\mathrm{Ru}(\mathrm{III})$ reduction potential for this complex is several hundred millivolts lower than for the parent complex $\mathrm{Ru}(\mathrm{dcb})_{3}{ }^{4-}$, but the kinetics for the energy-wasting back-ET reaction are not significantly accelerated. ${ }^{47}$

Nonadiabaticity (inefficient electronic coupling) clearly is an important contributor to the diminution of back electron-transfer rates. Introduction of appropriate spacers, such as semirigid alkanes, as part of the dye-to-surface linkage chemistry should further diminish electronic coupling and further decrease back electron-transfer rates. The rate decreases, in turn, should ultimately yield increased photovoltages and, therefore, increased energy conversion efficiencies. Spacer introduction would, of course, also be expected to diminish forward electrontransfer rates ("dye injection" rates) and, eventually, dye injection yields. Nevertheless, if dye injection is extremely fast in comparison to dye excited-state decay, then a few to several orders of magnitude decrease in injection rate could be introduced without significantly sacrificing injection yields.

\section{Conclusions}

Intentional variations of the driving force for back electron transfer from titanium dioxide to a surface-bound dye, via variation of the metal-based dye formal potential, show that the reaction takes place in the Marcus normal region; i.e., rates 
become faster as the driving force increases. Variable-temperature rate measurements show that back ET is thermally activated, with the activation barrier decreasing with increasing driving force, as expected for a normal region process. The observation of normal region behavior, despite the existence of overall reaction driving forces that exceed the likely reorganization energy, is attributed to the occurrence of a trap-localized, sequential electron- and proton-transfer process. The sequential process yields a driving force for the rate-determining electrontransfer step that is considerably smaller than the overall reaction driving force. The sequential electron- and proton-transfer mechanism also provides an explanation for the $\mathrm{pH}$ independence of the back-ET kinetics.

Variable-temperature rate measurements also point toward a high degree of nonadiabaticity $-3-5$ orders of magnitude of rate attenuation due solely to inefficient electronic coupling. The physical basis for the effect presumably is in the need to traverse eight bonds, some of them saturated, in the back-ET process. Together with the barrier activation effects, the reaction nonadiabaticity accounts for the slow rates for back ET (ca. $10^{7} \mathrm{~s}^{-1}$ ) and, therefore, much of the ability of Ru(bpy) $3^{2+}$-type chromophores to function effectively as sensitizers in $\mathrm{TiO}_{2}$-based photoelectrochemical cells. The findings also suggest that more efficient cells might be constructed by extending the chemical linkage between the dye and semiconductor and by further decreasing the driving force for the back-ET process.

Acknowledgment. We thank Fred Vance for generous assistance with data analysis. We thank the Office of Naval Research for financial support. S.G.Y. and J.S.P. additionally acknowledge partial fellowship support from the Materials Research Center at Northwestern (Grant NSF DMR-9632472) and the Link Foundation, respectively.

\section{References and Notes}

(1) Hagfeldt, A.; Grätzel, M. Chem. Rev. 1995, 95, 49.

(2) Kamat, P. V. Chem. Rev. 1993, 93, 267.

(3) Meyer, G. J.; Searson, P. C. Interface 1993, 2, 23.

(4) Lu, H.; Prieskorn, J.; Hupp, J. T. J. Am. Chem. Soc. 1993, 115, 4927.

(5) Hannappel, T.; Burfeindt, B.; Storck, W.: Willig, F. J. Phys. Chem. B 1997, 101, 6799 .

(6) Tachibana, Y.; Moser, J.; Grätzel, M.; Klug, D. R.; Durrant, J. R. J. Phys. Chem. 1996, 100, 20056.

(7) Vlachopoulos, N.; Liska, P.; Augustynski, J.; Grätzel, M. J. Am. Chem. Soc. 1988, 110, 1216.

(8) Desilvestro, J.; Grätzel, M.; Kavan, L.; Moser, J. J. Am. Chem. Soc. 1985, 107, 2988.

(9) Clark, W. D. K.; Sutin, N. J. Am. Chem. Soc. 1977, 99, 4676.

(10) Meyer, G. J. J. Chem. Educ. 1997, 74, 652 and references therein.

(11) Argazzi, R.; Bignozzi, C. A.; Heimer, T. A.; Castellano, F. N.;

Meyer, G. J. J. Phys. Chem. B 1997, 101, 2591.

(12) Fessenden, R. W.; Kamat, P. V. J. Phys. Chem. 1995, 99, 12902.

(13) Vinodgopal, K.; Hua, K.; Dahlgren, R. L.; Lappin, A. G.; Patterson,

L. K.; Kamat, P. V. J. Phys. Chem. 1995, 99, 10883.

(14) Yan, S. G.; Hupp, J. T. J. Phys. Chem. 1996, 100, 6867.

(15) See, for example: Argazzi, R.; Bignozzi, C. A.; Heimer, T. A.; Castellano, F. N.; Meyer, G. J. J. Am. Chem. Soc. 1995, 117, 11815.

(16) Marcus, R. A. J. Chem. Phys. 1965, 43, 679.

(17) For a review of electron transfer theory, see: Newton, M. D.; Sutin, N. Аnпи. Rev. Phys. Chem. 1984, 35, 437.

(18) Two recent reports have convincingly argued that back ET can, under many conditions, be driving-force-independent (Hasselman; Meyer. J. Phys. Chem. B 1999, 103, 7671. Tachibana, et al. J. Phys. Chem. B 2000 , $104,1198)$. Briefly, overall rate control is ascribed to slow, thermal-neutral hopping between deep trap sites, with exoergic interfacial ET occurring as a fast following step. The trap-site-hopping mechanism may well be operative here at longer times and, perhaps, at lower incident light intensities

(19) Moser, J. E.; Grätzel, M. Chem. Phys. 1993, 176, 493.

(20) Preliminary, ambient temperature results for three of the seven systems examined have been noted: Yan, S. G.; Lyon, L. A.; Lemon, B. I.; Prieskorn, J. S.; Hupp, J. T. J. Chem. Educ. 1997, 74, 657.
(21) For an example of inverted interfacial ET involving noncovalently bound polypyridyl ruthenium chromophores, see: Dang, X.; Hupp, J. T. J. Am. Chem. Soc. 1999, 121, 8399.

(22) Lyon, L. A.; Hupp, J. T. J. Phys. Chem. B 1999, 103, 4623.

(23) Lemon, B. I.; Hupp, J. T. J. Phys. Chem. B 1997, 101, 2426

(24) Lyon, L. A.; Hupp, J. T. J. Phys. Chem. 1995, 99, 15718.

(25) Lemon, B. I.; Hupp, J. T. J. Phys. Chem. 1996, 100, 14578

(26) Lemon, B. I.; Lyon, L. A.; Hupp, J. T. In Nanoparticles and Nanostructured Films; Fendler, J. H., Ed.; Wiley-VCH: New York, 1998; pp 335-348.

(27) O'Regan, B.; Moser, J.; Anderson, M.; Grätzel, M. J. Phys. Chem. 1990, 94, 8720

(28) Cleare, M. P.; Griffith, W. P. J. Chem. Soc. A 1969, 372.

(29) Black, D. S. C.; Deacon, G. B.; Thomas, N. C. Aust. J. Chem. 1982, 35,2445

(30) Black, D. S. C.; Deacon, G. B.; Thomas, N. C. Inorg. Chim. Acta 1982, 65,75 . 2647.

(31) Crutchley, R. J.; Lever, A. B.; Poggi, A. Inorg. Chem. 1983, 22,

(32) See, for example: Trammell, S. A.; Meyer, T. J. J. Phys. Chem. B 1999, 103, 104

(33) Yan, S. G.; Hupp, J. T. J. Phys. Chem. B 1997, 101, 1493.

(34) Lin, C. T.; Böttcher, W.; Chou, M.; Creutz, C.; Sutin, N. J. Am. Chem. Soc. 1976, 98, 6536.

(35) Note that too little of the second decay component is captured to establish whether it is exponential. Furthermore, too little is captured to determine $k_{2}$ with useful precision. An alternative fit of the transient in Figure 1 to a single-exponetial decay plus a constant yielded $k_{1}=1.2 \times$ $10^{7} \mathrm{~s}^{-1}$

(36) Williams, G.; Watts, D. C. Trans. Faraday Soc. 1971, 66, 80.

(37) See, for example: Ford, W. E.; Rodgers, M. A. J. J. Phys. Chem. 1994, 98,3822

(38) While it would be difficult to argue that the $k_{1}$ values for complexes $\mathbf{2}, \mathbf{3}$, and $\mathbf{4}$ are meaningfully different for the data set summarized in Table 2 and Figure 2, activation enthalpy measurements (Table 3 and Figure 4) clearly show that their reactivities can be differentiated and that the differences correlate with the driving force.

(39) If no high-frequency vibrational modes are involved (possibly the case here, given the metal-centered nature of the reaction), then modest activation enthalpies would be predicted even under inverted conditions. For illustrative calculations, see: Brunschwig, B. S.; Sutin, N. Comments Inorg. Chem. 1987, 6, 209; see also ref 21.

(40) Clark and Sutin (ref 9) have suggested that the reorganizational energy $(\lambda)$ required for $\mathrm{Ru}(\mathrm{bpy}) 3_{3}{ }^{3+}$ reduction at a titanium dioxide/solution interface could be as small as $0.2 \mathrm{eV}$. If image stabilization effects are absent, then $\lambda$ should double. If, in addition, lattice reorganizational effects are included (ca. $0.1 \mathrm{eV}$ based on resonance Raman studies (Blackbourn, R. L.; Johnson, C. S.; Hupp, J. T. J. Am. Chem. Soc. 1991, 113, 1060)), $\lambda$ is likely to be at least $0.5 \mathrm{eV}$. Very recently, however, in an extension and expansion of the work on noncovalently bound dyes, described in ref 21 , we have obtained from the maxima in the plots of rate vs driving force, and activation enthalpy vs driving force, estimated reorganization energies exceeding $1 \mathrm{eV}$ (Gaal, D. A.; Hupp, J. T. Manuscript in preparation).

(41) One possibility would be that back ET occurs from deep traps, such that the true driving force is much smaller than the driving force obtained from the difference in energy between the conduction band edge and the dye's formal potential. Direct measurements of the overall back reaction thermodynamics via time-resolved photoacoustic spectroscopy show, however, that the driving forces are not anomalously small (Leytner, S.; Hupp, J. T. Unpublished studies).

(42) $\mathrm{pH}$-dependent back-ET rate constants have been observed for polypyridyl ruthenium dyes electrostatically bound to $\mathrm{SnO}_{2}$, where the reactions indeed do appear to involve transfer directly from the bottom of the semiconductor's conduction band (see ref 21).

(43) Huang, S. Y.; Kavan, L.; Exnar, I.; Grätzel, M. J. Electrochem. Soc. 1995, 142, L142.

(44) Kavan, L.; Kratochvilova, K.; Grätzel, M. J. Electroanal. Chem. 1995, 394, 93.

(45) Kavan, L.; Grätzel, M.; Rathousky, J.; Zukal, A. J. Electrochem. Soc. 1996, 143, 394.

(46) See, for example: Hupp, J. T.; Weaver, M. J. Inorg. Chem. 1984 $23,256$.

(47) It should be noted that the best dye-sensitized solar cells operate in nonhydroxylic solvents, typically with a lithium-containing electrolyte. It is conceivable-perhaps even probable-that a mechanism distinctly different from Scheme 1 applies under those conditions. The scheme relies upon the ready availability of charge-compensating cations, a requirement that is easily satisfied in an aqueous environment, even under basic conditions, simply by abstracting protons from water. In cells containing nonhydroxylic solvents, charge compensation would instead be provided by $\mathrm{Li}^{+}$. If cation adsorption effects can be excluded, limits on $\mathrm{Li}^{+}$availibility would likely create significant short-time diffusive kinetic constraints even 
Driving Force Dependence of ET Reactivity

in concentrated (say, $0.5 \mathrm{M}$ ) electrolyte solutions, thereby rendering Scheme 1 less than fully applicable. Additionally, there is evidence to suggest that the "fast" kinetic component studied here is absent or greatly diminished in nonhydroxylic solvents under conditions of low incident light intensity
J. Phys. Chem. B, Vol. 104, No. 46, 200010877

(G. J. Meyer, private communication). If the observation is true for all dyes in nonhydroxylic solvents, then Scheme 1 would be significant only in aqueous solar cells or only in the context of fundamental investigations of interfacial electron transfer. 